4. Osawa, G. - Beiträge zur Lehre von des Sinnesorganen der Hatteria punctata. Arch.f. mikr. Anat. und Entwickl., Bd. LII, 1898.

- Ueber die Fovea Centralis von Hatteria punctata. Eine Erwiderung an Prof. Kailius in Göttingen. Anat. Anz., Bd. XV.

5. Kallius.-Ueber die Fovea Centralis von Hatteria punctata. Anat. Anz., Bd. XIV.

6. Mann, I.-Iris Pattern in the Vertebrates. Trans. Zool. Soc., Pt. 4, 1931.

7. Lindsay Johnson,-Contributions to the Comparative Anatomy of the Mammalian Eye, chiefly based on Ophthalmoscopic Examination. Phil. Trans. Roy. Soc., 1901.

8. Gamgee.-Text-Book of Physiological Chemistry of the Animal Body. Vol. I, p. 454, Macmillan, 188 n.

9. Ovio.-Anatomie et Physiologie de l'Oeil dans la Série Animale. Paris, 1927.

10. Detwiler and Laurens.-Studies on the Retina: the Structure of the Retina of Phrynosoma cornutum. Journ. of comp. Anat., Vol. XXXII, 3, pp. 347-356, 1920.

\title{
PENETRATING WOUNDS OF THE POSTERIOR CHAMBER OF THE EYE
}

\author{
BY \\ W. A. GRAY \\ LONDON \\ PART I
}

FIFTY-THREE cases of wounds of the sclera and other coats of the eye exposing the vitreous, were collected chiefly from Sir John Parsons' clinic at Moorfields; of these eighteen were in the region of the limbus and thirty-five were purely scleral wounds. The period covered was from 1905 to 1931 . The above numbers do not include sixteen cases where the injury was so extensive that immediate excision was the only possible treatment.

In the present investigation special attention was paid to the question of immediate infection. It was found that no case of acute infection was observed when the wound was scleral exposing the vitreous. Threatened sympathetic ophthalmitis occurred in five cases, four of which were injuries in the region of the ciliary body, and one was scleral. This is in accordance with the accepted view of the greater liability to sympathetic infection in the case of wounds involving the ciliary region.

Nature of the Injuries. The majority of the injuries were produced by hot fragments of steel. Four were caused by splinters of glass and one of stone. In two cases the injury was due to direct blows from a spanner. Small pieces of steel are usually sterile and rarely convey bacteria into the interior of the eye. At the same time a prolapse or exposure of vitreous to any organisms which may be present in the conjunctival sac is effected. In one case there were 
obvious signs of inflammation of the conjunctiva. Unsuccessful attempts had been made to remove a piece of steel from the vitreous. Three days later the case was sent to hospital when a wound of the sclera with vitreous prolapsing through it was found, with mucous discharge from the conjunctiva and blood in the vitreous. There was no subsequent infection of the vitreous and resulting vision was $6 / 36$.

The time elapsing between receiving the injury and admission to hospital varied from a few hours to seven days.

Symptoms and Signs. It was the injury which brought these patients to hospital and they could be further divided into those who complained of mistiness of vision of the affected eye and those who did not. This is an important point, for mistiness of vision usually is due to the occurrence of vitreous haemorrhage along the track of the foreign body.

There was no pain, lacrimation, or spasm of the orbital muscles, as is commonly met with in a similar injury to the cornea. Smirnow found that nerve endings were not numerous in the sclera of the human eye, and this probably accounts for the relative absence of signs of irritation.

The principal signs (in addition to the scleral injury with vitreous presenting) are intra-ocular haemorrhage in fanlike masses, lowered intra-ocular tension from vitreous loss, with increased depth of the anterior chamber. In the absence of haemorrhage, localised clouding of the vitreous in the path of the foreign body can be seen. But this depends on the size of the particle and may be absent in the case of a very fine fragment. Von Thornber (1909) showed that penetration of the vitreous with a needle of three millimetres diameter produced no change, with a thicker needle there was cloudiness in its track. Cases have been recorded where the foreign body remained suspended for a time in the vitreous.

Infection of the Vitreous following Sclerotic Injuries. It has been shown by many investigators that the vitreous is susceptible to bacteria and has very little resistance against them. Weber in 1860 , Pagenstecher 1870 , obtained virulent inflammation on injecting pus from a tear sac into the vitreous. Gifford (1886) used microorganisms from the conjunctival sac, Perles (1895) sarcinae lutea, and B. subtilis, Deyl (1893), Axenfeld with Katalska (1897), B. xerosis, and after a long interval got inflammation. Leber (1591) used moulds to obtain purulent infiltration of the vitreous. Axenfeld says " many bacteria multiply and develop a very severe inflammatory reaction although in other parts of the eye they would remain encapsulated." He cites B. subtilis "only slightly irritating in the anterior chamber, can produce fulminating suppuration in the vitreous." More recently Cronstedt (1923) agrees as to the good cultural powers of the vitreous. 
In injuries of the posterior chamber of the eye infection may result in two ways. The bacteria may be carried into the vitreous with the foreign body or they may subsequently enter from the conjunctiva through the scleral wounds. Szánté designates these as primary and secondary.

Primary Infection.- In the present series of cases it has been pointed out that most of the injuries were produced by fine fragments of steel which were heated and therefore sterile, so that few, if any, bacteria would be carried in by them, and this is borne out by the absence of infection. There was only one case of shrapnel injury. War wounds, on the other hand, were produced by irregular pieces of steel and stone which by their irregular surface, rendered adherence of infective material easy. In addition many were indirect injuries, i.e., the missiles in many instances first struck the ground and were then deflected into the eye. Many wounds were caused by shell and mine explosions. Thus infection was more common with this type of injury in the war. Lister (1918), Hertel (1922). Lister, however, states that panophthalmitis following war wounds is not of an acutely virulent type. Further, in the official History of the War it is noted that removal of the foreign body was rarely followed by septic complications.

Other records show a certain incidence of panophthalmitis. Goulden had seven cases, all of them cornea and lens injuries, in 118 penetrating injuries of the eye. In Brownlie's series, out of 17 purely scleral wounds two developed panophthalmitis. Allport reports panophthalmitis in 10 instances from 90 scleral wounds. On the other hand, cases of scleral injuries with retained foreign body have been reported by Fisher, Maitland Ramsay and others, which made excellent recoveries following removal of the fragment.

It is evident that bacterial inflammation of the vitreous occurs in a certain percentage of cases and is dependent on the nature and size of the entering fragment.

Secondary Infection.-When vitreous is prolapsed through a scleral wound which is also bounded by portions of the choroid and retina, it is not only exposed to any micro-organisms contained in the conjunctival sac, but a pathway is established leading into the interior of the posterior chamber where bacteria could find what would appear to be excellent conditions for their growth and propagation. Duane, in the revised 7th edition of Fuchs' text book contrasts the good prognosis of wounds of the anterior segment of the eye where aqueous flows out and washes the wound, with those of the posterior segment. In the latter he states "the vitreous sticks in the wound and affords a convenient path for the entrance of germs." Similar views are held by de Schweinitz. Friedenwald says there is no living cell in the vitreous and Anderson states "that bacteria spreading in from the neighbouring parts are free 
from the inhibiting action of the tissues. They multiply rapidly and abscess formation occurs."

Axenfeld has stated that the normal conjunctiva contains regularly B. xerosis and non-virulent staphylococcus albus. Two cases are reported of inflammation following cataract extraction where only white staphylococci were found. Bach found twenty-seven varieties of bacteria in one hundred conjunctivae. It is apparent, then, that a prolapse of vitreous will have ample opportunities of coming into contact with many different bacteria.

Prolapse of vitreous was present in a marked degree in fourteen cases of the present series. The duration of exposure was in some cases two to three days. In one patient there was obvious infection of the conjunctiva for three days, whilein another seven days were allowed to elapse before treatment was sought. Yet in all these instances no infection of the vitreous resulted, and useful vision was obtained.

The amount of exposure of the vitreous was dependent not only on the size of the wound, but also on its direction. The sclera consists of connective tissue bundles arranged meridionally and equatorially. According to Salzmann the equatorial arrangement predominates in the neighbourhood of the optic disc and in the scleral roll immediately external to the cornea. More external to this roll the fibres, especially the superficial ones, have a meridional direction, and as this part is immediately under the bulbar conjunctiva it is the part which is injured, the area of sclera behind the equator being well protected by muscles, etc. It will be seen that a meridional injury of the sclera will not gape, and thus less vitreous will be exposed. Further, the overlying conjunctiva will tend to close over the wound and lend additional protection. There were twelve such wounds in our series. The remainder, however, were in the direction across the long axis of the scleral fibres and their margins were therefore drawn apart. In addition, cases occurred where a piece of the scleral wall was missing, and it was in the latter that marked prolapse of vitreous had taken place.

There is thus no clinical evidence in the present series for the view that a prolapse of vitreous affords entrance to the interior of the vitreous of destructive bacteria. In the second section of this paper experimental proof will be given that exposed vitreous has considerable powers of resistance against bacterial infection.

Loss of Vitreous. This occurred in five cases to a considerable degree and was evidenced by the low tension and the increased depth of the anterior chamber. They had no haemorrhage. The direction of the wound was meridional 2, equatorial 2, and the remaining one with a large transverse wound of the cornea opening up the sclera on each side. The amount of vitreous lost seems to be dependent on the amount of the initial trauma. It is least in 
injuries produced by a small fragment travelling at great velocity. In some of these cases the initial wound was quite small. Vitreous, once the initial injury was past, did not tend to drain away. It adheres to the margins of the wound, for in several cases the tension was not very much diminished although there was a fair sized scleral wound ( $3 \mathrm{mms}$. by $2 \mathrm{mms}$.).

The vitreous has been described as consisting of a thickened anterior border behind the ciliary body and lens, and a posterior border beginning at the ora serrata, becoming thinner posteriorly (v. Szily, Woolfrum, Fischel). Retzius described fasciculi which are thicker and close together at the periphery. Virchow and Greeff also hold that it possesses a definite structure. Lauber believes that by virtue of a thickened outer zone the vitreous in accidental or operative wounds can appear without any loss and under favourable conditions can withdraw again, as for example, after discission following cataract extraction. This thickening of the outer part of the vitreous could explain cases of scleral wound where there is evidence of little loss of vitreous. Baurman, however, from his investigations with the ultramicroscope believes that the vitreous is an undifferentiated gel and that the appearances seen in microscopic sections can be attributed to the effect of fixatives used.

Loss of vitreous did not apparently hinder the subsequent recovery of vision. The normal tension of the eyes was quickly established after the scleral wound had been covered with a conjunctival flap. This was due to the outpouring of fluid by the ciliary body. Löwenstein and Samuels hold that one-third of the vitreous volume can be lost without serious effects. The danger is that a sudden loss will cause a detachment of the retina. Ford (1890), Elschnig (1911), zur Nedden (1920), advocate withdrawal of vitreous in infection. Birch-Hirschfeld reported that a considerable number (72 percent) of cases of detached retina had occurred. Hudson has drawn attention to the frequency of serous detachment of the choroid in perforating injuries when the ocular tension remains low. There were in the present series three cases of injury with extensive detachments of the retina; one of them was seen one month after the initial trauma. It is interesting to note that none of them suffered much loss of vitreous at the time of the accident. As the original five cases of extensive vitreous loss were not followed up it is impossible to speak of the ultimate prognosis, for detachment of the retina has been reported after two years, Zazkin (1905), four years, Mergel (1903), eight years, Scharg (1907). In one of our cases detachment ensued after two years. This patient had 6/9 vision thirteen months after the injury, vitreous was clear; there was an anchored opacity below at the site of the scar. These cases of late detachment were probably due to the pull of fibrous tissue which fills the site of the original wound. This explanation, of course, 
cannot account for cases of early or immediate detachment. In the latter it would seem that the amount of the original trauma more than vitreous loss, was the deciding factor.

Haemorrhage. Haemorrhage into the vitreous was present in eleven cases. The amount varied from profuse haemorrhage necessitating excision of the eye to a fine streak in the path made by the foreign body. Wounds at the extreme periphery of the retina show the least amount for there the vessels are small. The size of the wound of the sclera was not strictly proportional to the amount of haemorrhage, for in a small wound a vessel of considerable size can be divided. The fall in intra-ocular tension has been shown to lead to retraction of the retinal and choroidal vessels and their elastic coats can exert their whole pressure on the blood stream (Parsons).

Typically the blood occurs in fan-shaped masses along the track of the missile. This is attributed by Lister to the splitting of the vitreous by the initial trauma. Fuchs says that haemorrhage fills the space between the vitreous and retina but Lauber considers that this is due to the blood tearing the vitreous away from the retinal surface. Birch-Hirschfeld (1909) on aspirating vitreous found it separated from the retina.

In the absence of haemorrhage it was found that the vision was little impaired. Where haemorrhage has occurred there is a gradual clearing of the vitreous but the vision seldom returns to normal. Also the presence of haemorrhage leads to the formation of fibrin and although this is mostly absorbed by polymorphonuclear leucocytes, the new fibrous tissue formed by the mesoblastic element of the choroid and episcleral tissue is increased so that a dense scar is formed which may from its bulk impair vision. This was noted in four cases. Most of these eyes are lost subsequently.

Phthisis Bulbi.-Shrinkage of the eyeball was observed in three cases, all of them scleral wounds. There was diminution of ocular tension, the cornea flattened and became smaller. The anterior chamber became shallow and there was haemorrhage from the iris. Similar results have been reported by Goulden, Ramsay and others. These cases are probably either due to trauma or to a chronic infection.

Trauma.-Whether the vitreous be an undifferentiated gel or a tissue there must be some relation between the fibrils and the fluid part. The fluid, according to Raeder, is adsorbed to the fibrils. The amount adsorbed probably depends on the pressure and also on the chemical changes in the fluid. This relationship is a delicate one and liable to be upset easily by external influences such as trauma resulting from a penetrating steel fragment. Löwenstein estimates the albumin content of the vitreous as 0.02 per cent., while the subretinal fluid is rich in albumin. In the case of a 
detachment with a hole, this albuminous fluid will escape into the vitreous. The quantity of albumin also increases in other pathological conditions.

Haab's first consideration in removing foreign bodies was to traumatise the vitreous as little as possible.

The influence of haemorrhage on the vitreous is another factor which calls for consideration. Parsons says that the wounding of a large vessel "adds immeasurably to the severity of the condition." Fluidity of the vitreous results after absorption of a large haemorrhage (Lauber). The absorption of blood clot must also lead to a disturbance and damage of fibrils. Ellett has drawn attention to "through and through injuries where there is much bleeding even when the ciliary region is not involved, these cases tend to develop a chronic iridocyclitis with quiet periods leading to shrinkage." A certain proportion of cases of sclerotic injuries after removal of the foreign body tend to develop a type of plastic iridocyclitis.

Late Infection.-Late infection occurred in two cases of this series, both wounds of the limbus. Two months after the injury they were admitted to hospital with keratic deposits on the back of the cornea. Under treatment these disappeared with resulting vision of $6 / 36$.

Other cases of chronic infection have been reported. Deutschmann had a case of chronic inflammation with shrinkage. Approximately three years afterwards the eye was removed, and bacteria found. Another one, one and a half years after injury, showed cocci and diplococci in. the ciliary region. Berry and SchmidtRimpler give further evidence of the latency of bacteria in the eye. Chodorowsky injected measured quantities of staphylococcus aureus, streptococcus pyogenes and bacillus pyocyaneus, and by plating was able to obtain bacteria after 20 days, and 2 months (staphylococci), pyocyaneus after three months.

Lastly, an eye, which has been damaged by a penetrating foreign body, may have its function deranged and its resistance lowered. In such circumstances any bacteria which may be circulating in the blood from some distant focus may there find a suitable nidus to settle in.

It is thus difficult to assess the respective importance of trauma and infection in causing shrinkage of the eye.

The treatment adopted was to remove the foreign body through the scleral wound in cases where it was accessible, otherwise the anterior route was used.

\section{Summary}

Evidence has been brought forward to show that vitreous exposed through a wound of the posterior chamber of the eye did not become infected in the majority of cases. In fifty-three cases there 
was no panophthalmitis. Other figures give two out of seventeen, ten out of ninety. This refers to acute infection and seems to show that a prolapse of vitreous does not afford a ready entrance of bacteria into the interior of the posterior chamber.

A proportion of cases showed subsequent shrinkage of the eyeball, and it was difficult to determine to what extent bacteria were responsible for this.

\section{REFERENCES}

von Thorner.-Arch. f. Ophthal., Bd. LXIX, S. 391.

Weber.-Virchow's Arch., Bd. XVI, 1859; Bd. XIX, 1860.

Pagenstecher -Arch. f. Augenheilk., u. Ohrenheilk., Bd. I, 1870.

Gifford.-Arch. f. Augenheilk., Bd. XVI, 1886.

Perles.-Virchow's Arch., Bd. CXL, 1895.

Dey1.-Böhmische Akademie der Wissenschaft., 1893.

Katalska.-West. Opt., 1897.

Leber.-Die Entstehung der Entzündung, 1891.

Axenfeld.-Bacteriology of the Eye, p. 86, 1908.

Cronstedt.-Svenska lakaresallskapets handb., Bd. XLIX, H. 3, S. 157, 1923. Lister.-Lancet, July 20, 1918.

Hertal.-Handbuch der aertztlichen Erfah. in Weltkreige, Bd. V, Leipzig. 1922.

Szánté.-Klin. Monatsbl.f. Augenheilk., Bd. LIX, S. 76, 1917.

Goulden.-Roy. Lond. Ophthal. Hosp. Reps., Vol. XVII. part II.

Brownlie.-Ophthalmoscope, Vol. XIV.

Allport.-Amer. Jl. of Ophthal., Vol. VIII, p. 472, 1925.

Fisher.-Hunt. Lect., February 5, 1930.

Maitland Ramsay.-Eye Injuries and their Treatment, 1907.

Anderson.-Detachment of Retina. Camb. Press, p. 33, 1931.

Duane.-Fuchs' text-book. 7th edit. revised, p. 96.

Bach.-Arch.f. Ophthal., Bd. XL, H. 3, S. 5130, 1894.

v. Szily.-Anat. Anz., 24, Nr. 16 and 17; Anat. Hefte-Haft, 109, 1908.

Salzmann.-Anat. u. Hist. des Mensch. Augapfel, Leipzig, 1912.

Woolfrum.-Arch.f. Ophthal., Bd. LXV, S. 220.

Hudson.-Roy. Lond. Ophthal. Hosp. Reps., Vol. XIX, p. 301.

Retzius.-Ueber den Bau des Glaskörpers und der Zon. Mensch. August, 1894.

Virchow.-Ophthal. Ges., Heidelberg, 1885; Ergebn. d. Anat. u. Enburck., Bd X, S. 727.

Greeff.-Arch. f. Augenheilk., Bd. LIII, S. 119; Lehrbuch spec., Path., und Anat., III, Lieferung, 5583.

Baurman.-Arch. f. Ophthal., Bd. III, S. 352.

Löwenstein and Samuels.-Ophthalmology, January, 1915.

Ford.-Lancet, p. 462, 1890.

Elschnig.-Ueber Glaskorper ersatz. Bericht. ueber die 37 Vers., d. Ophthal. Gesellschaft, Heidelberg, 1911.

zur Nedden.-Arch.f. Ophthal., Bd. 101, S. 5145.

Parsons.-Roy. Lond. Ophthal. Hosp. Reps., Vol. XV, pp. 215-253.

Birch-Hirschfeld.-Exper. Stud. Netzhautabhebung. Forts. der Med. Nr. 13, 1911.

Haab.-Jn. Amer. Med. Ass., August 30, 1902.

Deutschmann.-Arch. f. Ophthal., Bd. XXXI, S. 527.

Berry.-Verhandl. d. X Internat.-Med. Congress, Bd. IV, H. 5, S. 125.

Schmidt-Rimpler.-Heidelberg Congress, 1891.

Chodorowsky. - Zur Frage der Lebensdauer einiger Bakt. in Auge. Inaug. Dissert., Petrograd.

Lauber.-Handbuch der ges. Augenheilk., Bd. V, 3rd Abl.

Ellett, E. C.-Trans. Amer. Ophthal. Soc., Vol. XXV, p. 64. 


\section{PART II}

\section{Introduction}

In the first section attention was drawn to the relative infrequency of panophthalmitis following penetration of the vitreous containing chamber of the eye by foreign bodies. This was to some extent explained by the aseptic nature of the entering fragment and the consequent absence of implantation of bacteria in the interior of the eye. At the same time, however, the wound of the sclera, choroid and retina incident on such injuries exposed the vitreous to the bacteria of the conjunctival sac, constituting a possible pathway for the entry of infection. Liability to infection on the part of the vitreous must therefore be estimated from two aspects, (1) where the bacteria were deeply placed in its interior, and (2) when the superficial part of the vitreous only was exposed.

Insertion of Bacteria into the centre of the Vitreous. In thirty rabbits virulent bacteria were introduced into the middle of the vitreous by means of a syringe, the needle penetrating the sclera, choroid and retina. In every case panophthalmitis resulted.

Bacteria. The following bacteria were used:-

(1) Bacillus pyocyaneus, five different strains. This microorganism was found to be the most virulent and this is in conformity with the well-known susceptibility of the rabbit to this bacillus. It thus constituted a severe test and was used in the majority of the experiments. Other organisms used were staphylococcus aureus, haemolytic streptococcus, bacillus coli, pneumococci, b. subtilis and a diphtheroid bacillus. Although these produced a less acute type of inflammation, the results conformed to those produced by bacillus pyocyaneus.

The number of bacteria used in each experiment was fifty million bacteria (judged by opacity) of a twenty-four hours culture on agar made from a fresh meat basis, suspended in normal saline.

Technique of Injection.-To avoid haemorrhage a point on the sclera away from the insertion of the muscles was chosen, and with the point of a keratome a small incision was made till vitreous presented in the wound. This was necessary because the toughness of the sclera prevents penetration by a needle. The sites chosen were the upper, lateral and lower fornices A hypodermic needle with attached syringe containing the bacterial suspension was used for the injection, but before this was done a quantity of vitreous slightly greater than the amount to be injected was withdrawn. This prevented the vitreous forcing the entering suspension into the subconjunctival space. The needle was inserted to a depth of five millimetres from the conjunctival surface into the vitreous in a backward and inward direction, and its position verified by ophthalmoscopic examination. Only rabbits with normal fundi were used. The amount of the suspension injected was one drop ( 001 c.c). The trauma inflicted by this operation was confined to that produced by the local incision through the sclera and other coats of the eye. All rotatory movements were avoided. 


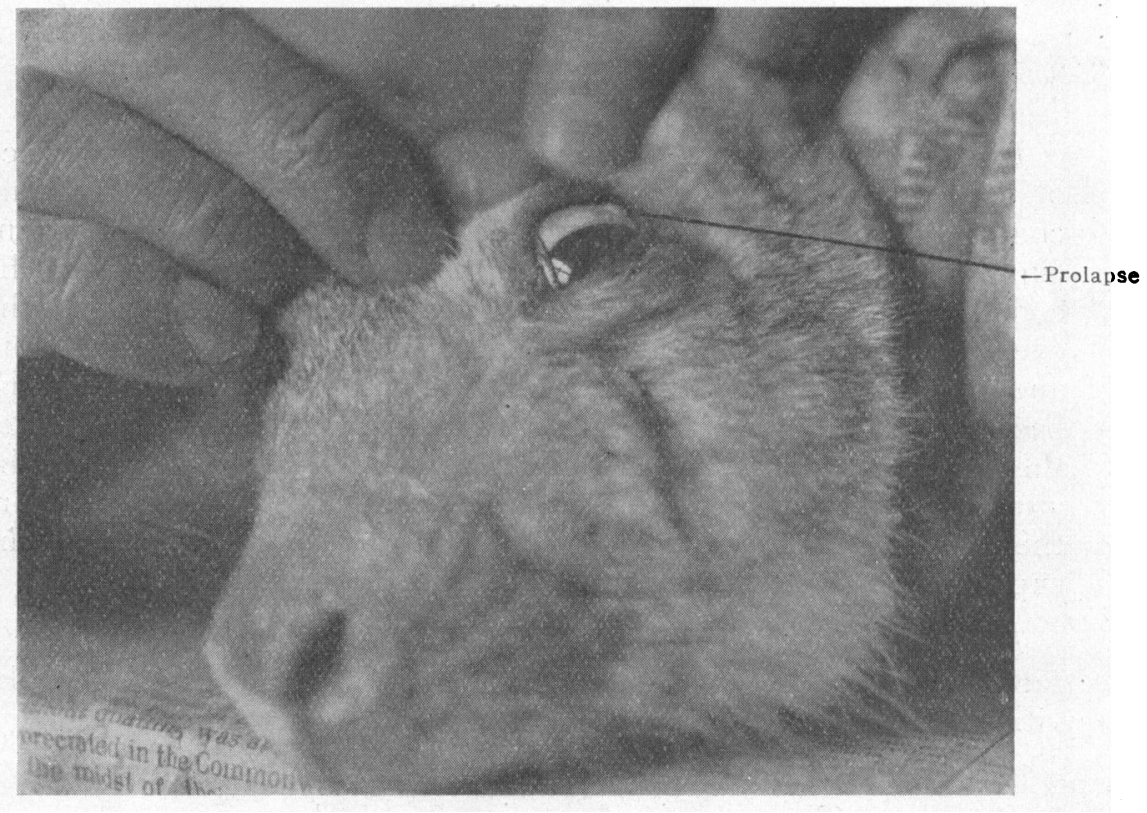

Prolapse under a flap.

\section{Description of Inflammation}

(1) Clinically. An effusion behind the lens, between its posterior capsule and the anterior part of the vitreous appeared in twelve hours and obscured the fundus. Congestion of the conjunctiva did not appear till twenty-four hours after the injection. It was accompanied by slight conjunctival discharge. The cornea was clear and the most characteristic sign was the ground-glass appearance on the posterior surface of the lens which was due to the effusion noted above. As infection proceeded, the conjunctival congestion increased but there was never much discharge until the cornea became secondarily infected. At the end of the second day pus appeared in the anterior chamber and some oedema of the lower part of the cornea. This proceeded to the development of an abscess. Perforation occurred on the third day at the corneosclerotic junction. There was considerable constitutional effect and sometimes contraction of the neck muscles of the same side as the infected eye.

(2) Macroscopically. When such an eye in the early stages (twenty-four hours) was split open a thin layer of pus lay on the surface of the retina extending on to the posterior surface of the lens capsule. The vitreous was quite clear and was ringed round 
with pus. The depth of the surrounding layer of pus increased as infection proceeded and just before perforation, occupied an area equal to one-sixth of the total space. Penetration towards the centre was not very marked. There was less pus behind the lens than elsewhere.

(3) Microscopically. The earliest changes, as seen within two hours of infection, appeared to be a well marked extensive engorgement of the vessels of the choroid. Perivascular spaces not infrequently contained free red corpuscles, and at a slightly later period these could be seen passing into adjacent tissues, such as the retina, coming to lie on the surface of the vitreous. Polymorphonuclear leucocytes soon appeared, their deeply stained lobes standing out in marked contrast to the well stained erythrocytes. The site of infection appeared to be determined by the mode of introduction of the organism: the earliest reaction occurring in the ciliary region corresponding to the site of injection and frequently also at the optic disc area around the central vessels of the retina. At twelve hours, acute inflammation of the choroid and ciliary body was rapidly proceeding and the presence of numerous polymorphs in the anterior chamber of the eye and the ciliary process of the opposite side of the same eye, suggested an active spread of the infection. With the lapse of twenty-four hours a panophthalmitis had developed in most instances. In striking contrast was the almost complete absence of change in the vitreous. Spread from the neighbourhood of the ciliary body appeared to have been determined by the resistance of the vitreous; the region of the optic disc seems to have been an especially favourable site for the early development of infection and from here also the spread was superficial, so that two advancing zones of leucocytic infiltration could be seen passing forwards to meet those arising at the ciliary region.

In the later stages, from forty-eight hours onwards, the leucocytes had invaded the superficial layer of the vitreous forming a distinctive zone between the retina on the one hand and the vitreous on the other. The vitreous had thus become surrounded by a covering of leucocytes. Later the leucocytic infiltration between the vitreous and the retina appeared greatly to exceed that posterior to the lens.

The type of cell varied with the stage of the infective process. At first there was a simple engorgement of all the available blood spaces of the choroid with red corpuscles. This, in time, extended outwards to structures in Tenon's capsule and beyond to the orbital fat. Polymorphonuclear leucocytes appeared at an early stage and soon showed degenerative changes, their nuclei staining more deeply and becoming pyknotic. Histiocytes and lymphocytes were numerous. Smears from the central clear area of the vitreous were found to be free from cells and bacteria, whereas films from the periphery consisted almost entirely of leucocytes. Disorganisation 
of the retina occurred frequently with scattering of pigment cells. Not uncommonly, however, it appeared to be normal although in close proximity to inflammatory cells.

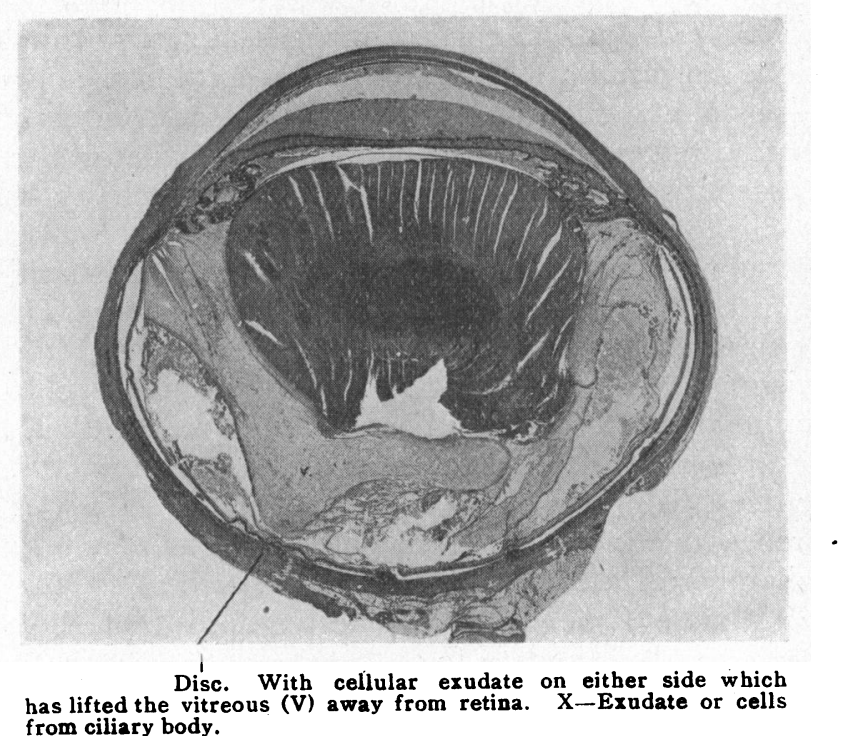

Deep injection (3rd day) of B.pyocyaneus into centre of Vitreous.

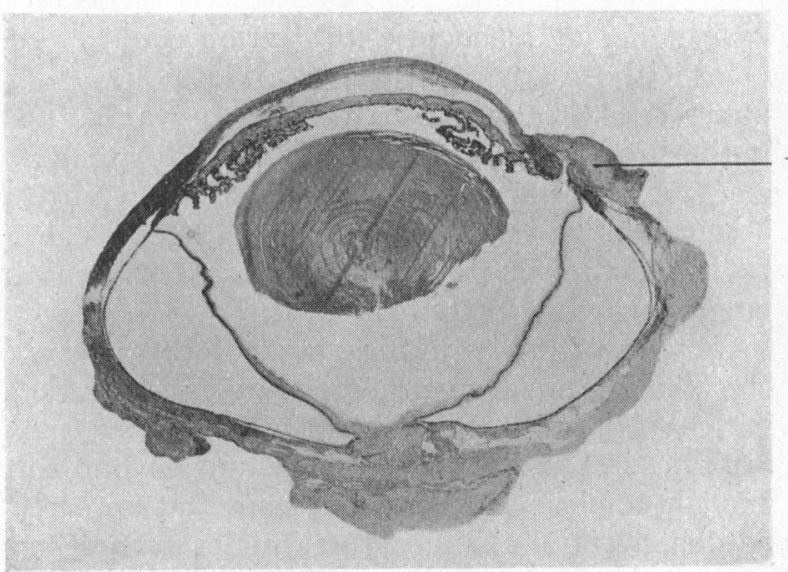

-Flap with prolapse beneath.

Whole Eye. Prolapse under flap (3rd day).

(Note retina has become detached from choroid.) No cells can be seen in Vitreous. 
Vitreous as a Culture Medium in Vitro.-The obtaining of 100 per cent. ratio of infection when micro-organisms are injected into the interior of the vitreous suggested that bacteria must there find excellent conditions for growth. This is in agreement with the generally held view. Vitreous was removed from the eye and used as a culture medium in the test tube when it appeared to be a reasonably good medium. For B.pyocyaneus it was comparable with such a highly specialised laboratory medium as nutrient broth, and in the case of B.subtilis, staphylococcus, pneumococcus and streptococcus, the growth of these organisms on vitreous never appeared less than one-twentieth of that obtained in broth.

Technique.-The vitreous wds aspirated under aseptic conditions from the rabbit's eye immediately after excision, twenty minims being placed in a series of tubes. As wide a tube as possible was used in aspirating to minimise the deformation of vitreous, on which much may depend in the response to infection. A tube of quarter-inch bore was found to be the most suitable. In every experiment, tubes with vitreous were set apart and incubated for one week to test the asepsis of the proceeding. The bacteria chosen were B.pyocyaneus, pneumococcus, staphylococcus aureus, B.coli and streptococci. Twenty-four hour cultures were used, and the amount injected was measured in each case. The enumeration was done by plating. The comparison was made with a similar amount of nutrient broth.

The following is an average of three experiments.

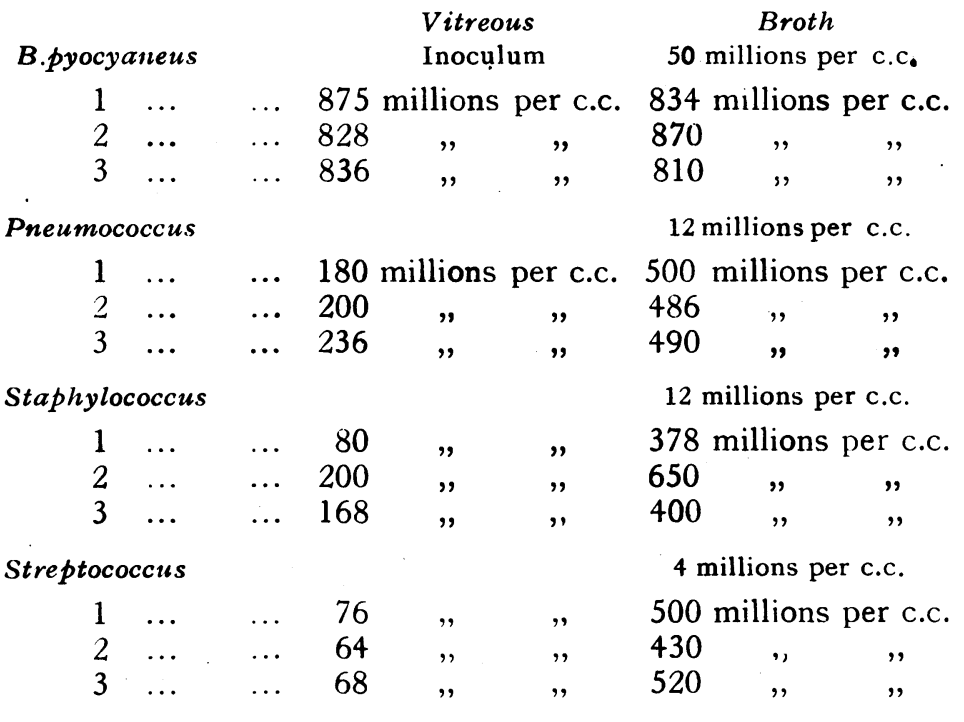

With exception of B.pyocyaneus, where the amounts of growth were equal, the other micro-organisms find vitreous not such a suitable medium as nutrient broth. But, that the vitreous is quite a good culture medium cannot be disputed, as in every case there was free multiplication of the original number of bacteria inoculated. 
Surface of the Vitreous. The second method of infection suggested was by active penetration of the surface vitreous by bacteria as it lies prolapsed through the margins of the wound. This was investigated by experiments in vitro and in vivo.

In Vitro Experiments. Although the vitreous when aspirated and removed to the test tube is a good culture medium, it is possible that the relatively intact vitreous with its gel structure preserved might prove an unsuitable medium for bacterial growth. An attempt was made to investigate this point by removing the entire vitreous with as little damage to its consistency as possible into a Petri dish. When carefully removed the vitreous maintains a semi-rigid consistency and it may be used as a medium for the surface growth of bacteria in the same way as agar medium. When the growth of an implant of staphylococcus on the surface of such a removed vitreous was compared with that of an equal area of ordinary agar medium, it was found that the growth on vitreous was much inferior to that of agar, but a sufficient number of colonies grew up on the vitreous to make it impossible to say that there was any real protection of an exposed vitreous surface against bacterial invasion. The discrepancy between the agar growth and that of the vitreous can probably be paralleled by the discrepancy between agar growth and growth of bacteria on any tissue or exudate. Staphylococci were used in this experiment because B.pyocyaneus tends to form a spreading colony on nutrient surfaces. Special sizes of Petri dishes were necessary owing to the small amount of vitreous available. Precautions were also taken against drying in the incubator by putting the special dishes into ordinary Petri plates containing sterile water.

The eyes were immediately excised after killing the rabbits and with aseptic precautions the vitreous was evacuated through an opening equal to half the circumference of the globe, into a number of the small dishes. An equal amount of suspension of a twentyfour hours growth of staphylococcus aureus was sprayed over the surface by means of a fine pipette to ensure uniform distribution. Nutrient agar (prepared with a fresh meat basis) was the medium used in comparison, under the same conditions as regards size of dish and amount of suspension of bacteria used. The inoculating culture was distributed so as to give twenty colonies on the agar plate.

After 48 hours

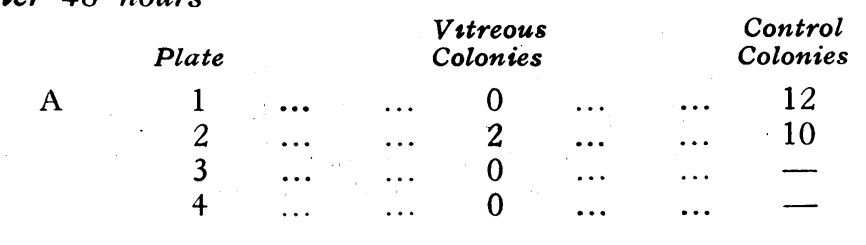


Bac̀terial suspension increased to 100 colonies

\begin{tabular}{llllllll} 
B & 1 & $\ldots$ & $\ldots$ & 8 & $\ldots$ & $\ldots$ & 147 \\
& 2 & $\ldots$ & $\ldots$ & 7 & $\ldots$ & $\ldots$ & 132 \\
& 3 & $\ldots$ & $\ldots$ & 0 & $\ldots$ & $\ldots$ & - \\
& 4 & $\ldots$ & $\ldots$ & 6 & $\ldots$ & $\ldots$ & - \\
& \multicolumn{8}{c}{ Bacterial suspension increased to } & 1000 colonies \\
& 1 & $\ldots$ & $\ldots$ & 6 & $\ldots$ & Uniform film of \\
& 2 & $\ldots$ & $\ldots$ & 9 & $\ldots$ & minute colonies \\
& 3 & $\ldots$ & $\ldots$ & 7 & $\ldots$ & impossible to \\
& 4 & $\ldots$ & $\ldots$ & 5 & $\ldots$ & enumerate
\end{tabular}

Although scanty growth was thus obtained on vitreous in the above experiments if the vitreous used was replated on to agar good growth of the bacteria was obtained. To determine whether the micro-organisms during their sojourn on the surface of the vitreous were diminished in number, measured amounts of B.coli, pyocyaneus, and staphylococci were placed (1) in normal saline, (2) on to plated vitreous, and at the end of 24 and 48 hours their number was determined. It was found that vitreous had caused no diminution in the numbers of the micro-organisms.

In vivo experiments. - The surface of vitreous as it prolapses through a wound of the sclera and other coats of the posterior chamber was inoculated with B.pyocyaneus. No general infection of the vitreous took place in eighty-six per cent. of cases.

The total number of rabbits used was ninety-six. Of these fortyeight were simply experiments in which a prolapse of vitreous was produced through a three millimetre incision. In the remainder, variations were made either to ensure a wider exposure of the vitreous or to exclude some additional factor such as the action of the lacrimal secretion or trauma. This latter group will be described in detail subsequently.

Technique.-The rabbit's eye was first examined to ascertain if normal. An incision was then made down to the vitreous three millimetres in length; when vitreous appeared in the wound the knife was turned at right angles and to ensure gaping, a slight cut was made. The positions chosen were the upper, middle and lower fornices.

To a twenty-four hours' growth of B.pyocyaneus on agar, made with a fresh meat basis, enough saline to extend half-way up the slope was added. A concentrated suspension of the bacteria was thus obtained. With this the conjunctival sac was filled, and the surface of the prolapsed vitreous covered with B.pyocyaneus. To ensure that the bacteria used were virulent, controls were established in each experiment-some of this suspension was injected into the centre of the vitreous of normal rabbits at the same time in the following way. A quantity of the suspension of B.pyocyaneus was placed in an all-glass syringe whose needle was then introduced $5 \mathrm{~mm}$. into the vitreous through a small keratome stab wound of the sclera choroid and retina. The barrel of the syringe was held perpendicular to the plane of the sclera. No pressure other than the weight of the syringe piston was used. The syringe was withdrawn as soon as the desired depth of penetration was obtained. 
All these controls developed panophthalmitis. Of the forty-eight cases of prolapsed vitreous, seven developed infection of the prolapse.

Variation of the Size of the Prolapse of Vitreous. The amount of vitreous which appeared in the wound was proportional to the size of the incision. In five rabbits three eyes were used as controls in the manner above described and prolapse of vitreous, over which suspension of $\mathrm{B}$. pyocyaneus poured, was obtained in the remainder by varying the length of the incision as follows :-

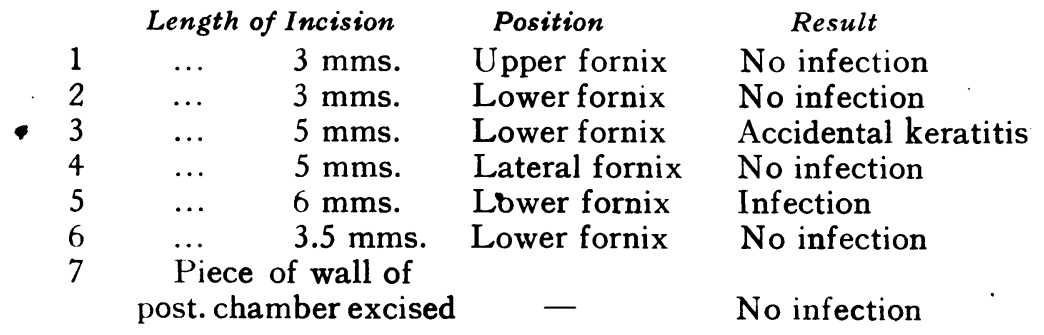

These rabbits were kept for seven days. In one out of seven cases of prolapse, infection resulted and this was with the maximum length of scleral wound. All the controls in which the vitreous was deeply infected developed panophthalmitis.

It may be stated that the wounds of the sclera which usually are met with clinically, are more open than those experimentally produced by a three millimetre knife-wound. To obtain a wide exposure of vitreous, a piece of the wall of the posterior chamber of the eye was excised. Six eyes were taken and three controls done by injecting the same suspension of $\mathrm{B}$. pyocyaneus $5 \mathrm{mms}$. into the vitreous. These produced inflammation and established the virulence of the strain of $B$. pyocyaneus used.

\begin{tabular}{|c|c|c|c|c|c|}
\hline & & Size of piece of & & Vitreous & \\
\hline No. & & wall excised & Position & loss & Result \\
\hline 1 & $\ldots$ & $3 \mathrm{mms}$. by $1.5 \mathrm{~mm}$. & Upper fornix & Yes & No infection \\
\hline 2 & $\ldots$ & $2 \mathrm{mms}$. by $1.5 \mathrm{~mm}$. & Outer fornix & Yes & No infection \\
\hline 3 & $\ldots$ & 2 mms. by 2 & Outer fornix & Slight & Infection \\
\hline 4 & $\ldots$ & $3 \mathrm{mms}$. by 2 & Lower fornix & Slight & No infection \\
\hline 5 & $\ldots$ & 3 mms. by 2 & Outer fornix & Slight & No infection \\
\hline 6 & $\ldots$ & $3.5 \mathrm{mms}$. by $2 . \mathrm{mms}$. & Lower fornix & Slight & No infection \\
\hline
\end{tabular}

These rabbits were kept for seven days, and one in six became infected when there was an exceptionally wide exposure of vitreous to proved virulent micro-organisms. The position of the prolapse appeared to be immaterial and did not alter the resistance of the vitreous to infection. From the above experiments it can be stated that prolapsed vitreous does not readily become infected at least with the organism experimentally used. This is in conformity with the clinical observation already referred to. The 
experimental conditions, the wide exposure of vitreous and the highly concentrated infective fluid constitute a more severe test than any condition which is likely to occur in clinical cases.

Effect of Lacrimal Secretion. The surface of prolapsed vitreous is exposed to the lacrimal secretion and it has been shown by Fleming that tears have a lytic effect on certain bacteria. So the growth of bacteria in vitreous was compared with that of vitreous to which $1 / 5$ of its volume of tears had been added. This was estimated by the method previously described. The following counts were made :-

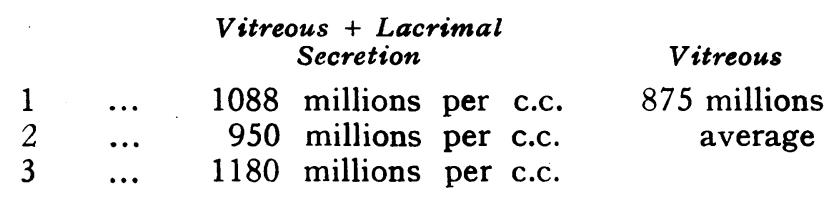

This showed that tears do not prevent the increase of bacteria.

Mechanical Action of Lids and Tears. In the above experiment it must be noted that the washing away effect was absent and the lacrimal secretion was not constantly renewed. To remedy this defect a number of rabbits (four) were taken and an incision through the conjunctiva down to the sclera was made. The flap was then dissected up for a distance of seven millimetres and a second incision made at this point into the posterior chamber through which vitreous prolapsed, forming a bead-like elevation. The flap was then allowed to relax and cover the prolapse. This prolapse was then injected with a suspension of B.pyocyaneus. Three control experiments were performed by injecting to a depth of $5 \mathrm{mms}$. into the vitreous the same suspension of $B$. pyocyaneus to prove its virulence. This was found to produce the typical inflammation. The result of the flap operations was absence of infection. Flaps were made in the outer and lower fornices. So no infection of the superficial layers of the vitreous resulted even when the action of the eyelids and of the tears was excluded.

Serum and Bacterial Growth. - The possible effect of serum on the growth of bacteria was investigated by comparison of the numbers obtained in vitreous to which the animal's serum had been added, but no appreciable difference was found.

Influence of Trauma as a Predisposing Cause of Infection.-The above experiment was repeated to estimate the effect of injection, using considerable pressure on the syringe piston, on the vitreous prolapse in half the cases.

Three controls were used where the needle containing a suspension of the same culture of B.pyocyaneus was introduced to a depth of $5 \mathrm{mms}$. Infection resulted.

No. of eyes where flap operation was done $=$ nine. 
Results.

\begin{tabular}{cclll} 
& & Position & \multicolumn{1}{c}{ Result } & $\begin{array}{c}\text { Pressure } \\
\text { used }\end{array}$ \\
1 & $\ldots$ & Lower fornix & Infection & Yes \\
2 & $\ldots$ & Upper fornix & Infection & Yes \\
3 & $\ldots$ & Outer fornix & No infection & Yes \\
4 & $\ldots$ & Outer fornix & No infection & Yes \\
5 & $\ldots$ & Lower fornix & No infection & No \\
6 & $\ldots$ & Lateral fornix & No infection & No \\
7 & $\ldots$ & Lower fornix & No infection & No \\
8 & $\ldots$ & Lateral fornix & Infection & No \\
9 & $\ldots$ & Lateral fornix & No infection & No
\end{tabular}

Three out of nine eyes, in which the prolapse was injected while covered with a conjunctival flap, became infected, of these two were cases where pressure had been used in making the injection. Counting the four eyes of the previous experiment, this gives three infected out of sixteen eyes.

In view of the two preceding experiments, it was resolved to produce the maximum damage while injecting the prolapsed vitreous, and at the same time to do the intra-ocular control with the minimal damage as hitherto. While all the control animals developed panophthalmitis, only two out of seven cases of prolapse became infected. These findings showed that with increased trauma there was an increased incidence of infection. If depth of penetration of the needle can be classed as trauma the next experiment was done to decide if this was also a factor. It was found that penetration of one millimetre depth resulted in no infection, depths of $1.5 \mathrm{~mm}$. gave delay in the onset of the ensuing inflammation, while depths of $3 \mathrm{mms}$. resulted in panophthalmitis.

It seems, then, that shallow penetration of the vitreous is not likely to be followed by infection and although this means less trauma it is also placing the bacteria in closer apposition to the extremely vascular choroid. As mechanical action at the surface or lytic action of the tears could be excluded, as an explanation of the relative insusceptibility of the prolapsed vitreous to infection, the possible significance of phagocytosis was investigated.

Lack of Histological Evidence of Phagocytosis. - This was obtained from two sources; (1) a series of flap operations $(12,24$, 36 hours) and (2) where the prolapse of vitreous was produced through a stab wound or a window was cut out of the walls of the posterior chamber. In addition a series of rabbits was taken and flap prolapses produced. They were killed from 48 hours onwards after the operation.

(1) In the first group the animals were killed at 12, 24 and 36 hours, so that any early emigration of phagocytic cells could be determined. In no case was there any leucocytic invasion of the vitreous, either of the prolapse or of the general vitreous body. At 
the most there was some engorgement of the structures in the subconjunctival space surrounding the prolapse, probably from trauma.

(2) This gave a more detailed picture of the happenings at the site of the prolapse and the changes due to trauma. They are discussed under microscopic changes at the prolapse.

Microscopic Changes at the Prolapse.-Prolapse of vitreous was produced in the following ways:-(1) Through a stab wound where the scleral incision lies immediately below that of the conjunctiva, (2) where a piece of the sclerotic and other walls is cut out, (3) prolapse of vitreous through a stab wound beneath a conjunctival flap.

The trauma of these methods varied. It was least in the stab wounds and greatest where a flap of conjunctiva was dissected up and a prolapse of vitreous made beneath it.

In dealing with the microscopic appearances those effects due to trauma must be carefully set aside from the histological changes due to exposure of the vitreous to a suspension in saline of B.pyocyaneus. The main change resulting from trauma was the formation of a small haematoma which was absorbed in the usual way.

At the prolapse vitreous is seen spreading between the edges of the incision in the sclera and other coats of the eye to form a globular surface supported at its periphery by the edges of the cut conjunctiva. It is normal looking and quite free from cells. At its periphery are a few cells consisting of histiocytes and young fibroblasts. An occasional polymorphar leucocyte is seen. There were no changes in the choroid or ciliary body, a finding in marked contrast to that accompanying deep inoculation of the vitreous. In

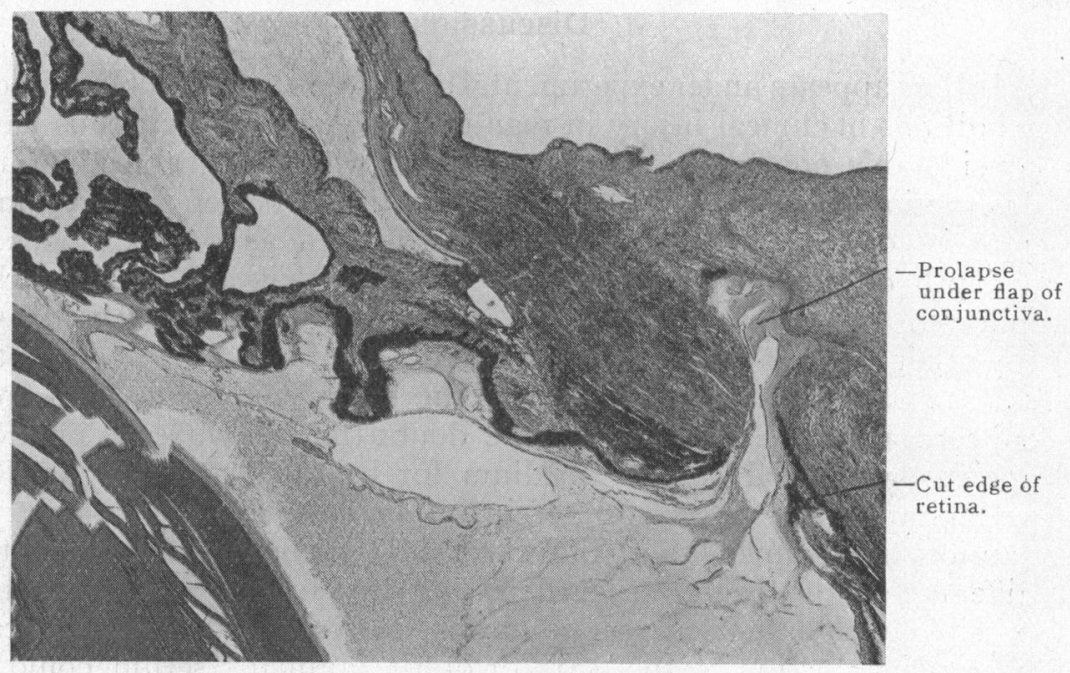

Prolapse of Vitreous under a Flap. 
the absence of bacteria as shown by negative results with Gram's staining; this reaction was almost entirely due to trauma associated with the operative procedure.

Exposure of vitreous to bacteria was not therefore accompanied by any phagocytic response which could be invoked to explain its immunity to infection. Although bacteria fail to obtain entry into the interior of the posterior chamber in a large percentage of cases in which vitreous is prolapsed through a scleral wound, they may be harboured on the surface of the exposed vitreous. An attempt to settle this point was made in two ways. First, in a series of rabbits in which a prolapse of vitreous under a conjunctival flap had been injected with B.pyocyaneus, the vitreous in the immediate neighbourhood of the flap was aspirated under sterile conditions by introducing the needle of a syringe through a puncture of the opposite side of the sclera. This was plated on to agar but no growth was obtained. Secondly, in another group of rabbits in which flap prolapsed vitreous had been exposed to infection, a large needle was passed through the opening in the sclera into the depths of the vitreous, in the hope that any bacteria might be carried into the interior of the vitreous. This resulted in negative findings. At the same times smears from the conjunctival sacs of these two sets of animals showed B.pyocyaneus in 40 per cent. of cases at the end of 24 hours, and 7 per cent. at the end of the third day. So although the micro-organisms persisted in the conjunctiva for some time there was no evidence of their penetration into the interior of the eye through the wound of the vitreous containing chamber.

\section{Discussion}

It thus appears under experimental conditions in the rabbit as under conditions of clinical injury in man that the prolapsed vitreous has a considerable power of resisting infection which might lead to the destruction of the eyeball. The injection of even a very small quantity of a virulent pyogenic organism such as B.pyocyaneus to a depth of $5 \mathrm{mms}$. or more into the vitreous is almost invariably followed by a rapidly destructive suppuration of the eyeball. On the other hand it was difficult to produce infection by flooding the surface of a vitreous prolapse with the same bacteria even in great concentration. There seems little doubt that the vitreous provides a reasonably good culture medium for bacteria, and it is hard to understand why the spread of infection does not take place. It cannot be claimed that the foregoing experiments explain this difference in the result of superficial and deep inoculation, but certain possible explanations appear to have been eliminated. No significant bactericidal action of the tears or of the animal's serum could be demonstrated. Nor was it possible to consider that the mechanical 
action of the eyelids or dilution and removal of the bacterial inoculum by tears, were responsible for the benign course of superficial prolapse. Bacteria in excess of those producing an invariable panophthalmitis on deeper inoculation could be introduced without effect into the surface of the prolapse while the latter was covered with a valve-like flap of conjunctiva. Although the position of the surface prolapse implies its close proximity to the vascular choroid, there was no histological evidence that phagocytosis of the inoculated bacteria played any significant part.

\title{
Summary
}

The remarkable resistance to destructive infection of the eyeball observed in cases of traumatic prolapse of the vitreous in man can be paralleled experimentally in rabbits using a highly virulent B.pyocyaneus as test organism. After exclusion of merely mechanical factors there still remains some significant difference in the resistance of the superficial and deeper layers of the vitreous.

My best thanks are due to Sir John Parsons for his continued interest in this work. To Professor C. C. Okell I am especially indebted for many valuable suggestions and for repeated help. Dr. G. R. Cameron has helped me with the histology.

The investigation was carried out in the bacteriological department of University College Medical School and the expenses were defrayed by a grant from the Medical Research Council.

\section{A CASE OF SEVERE SYMPATHETIC INFLAMMATION BROUGHT TO A SUCCESSFUL CONCLUSION}

\author{
BY \\ J. Herbert Fisher \\ LONDON
}

As an encouragement to surgeons confronted with the results of severe sympathetic ophthalmitis the following record of a case of this character should not go unpublished. In 1919 a boy, A.E.F., born in 1908, was using a fork with which to bore a hole in a leather belt, when one of the prongs penetrated his right eye. About four or five weeks after the accident the surgeon in charge of the case removed the injured eye. When the patient left the Nursing Home, the left eye was slightly bloodshot and inflamed; drops were used to it and an ointment for local inunction in the neighbourhood of the orbit. He continued to see his 